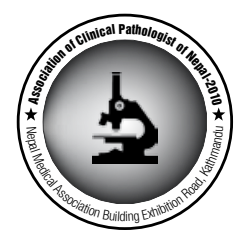

\title{
Cadaver kidney transplantation in Nepal: is it time to start?
}

\author{
Pant $\mathrm{AD}^{1}$ \\ ${ }^{1}$ Department of Pathology, Tribhuvan University Teaching Hospital, Kathmandu, Nepal
}

Dear Editor;

Kidney transplantation is a relatively newly introduced life-saving procedure in our country in which only living related persons are used as donors by law. In the previous issue of Journal of Pathology of Nepal, Enns J and Aryal G outlined "A Path to Renal Transplantation in Nepal."1 I would like to elaborate on one of its components, on developing a kidney cadaver transplant program.

A law for Cadaver Organ Donation needs to be formed in Nepal and passed. In India, the Organ Donation Bill was passed in 1995, but has still yet to gain wide acceptance, partly because of the religious beliefs of the people. ${ }^{2}$ Cadavers can be a huge source of organs which markedly helps reduce waiting times and can be lifesaving for transplant patients. More widespread availability of organs may also help reduce unscrupulous trading of organs which is so prevalent in our part of the world. Another step that could be used is to exclude living unrelated donor donation from the proposed law, in order to reduce such malpractice, such as selling and buying organs for money, or worse by force or trickery.

Survival of living unrelated donors versus cadaver kidneys has been shown to be comparable by Park et al. ${ }^{3}$ Traditionally, cadaver kidney transplants have a slightly lower overall survival, but with modern immunosuppression, there is even less of a gap comparing to living unrelated donors.

Since the kidney transplant program has already started in 2008, it is high time to think about this important next step. There is a lot of brainstorming, planning, discussion, and training of personnel required for passing the law and using cadaver organs for the benefit of kidney patients. Such steps are essential in order to further develop the kidney transplantation program in Nepal.

Corrrespondence:

Dr. Anil Dev Pant, M.D.

Department of Pathology

Tribhuvan University Teaching Hospital

Kathmandu, Nepal

Email address: adpant@yahoo.com

\section{REFERENCES}

1. Enns J, Aryal G. A Path to Renal Transplantation in Nepal. JPN 2011;1:52-5.

2. Mishra MN, Saxena VK, Narula AS. Differences in Renal Transplantation in India and First World Countries . Int J Hum Genet 2004;4:161-5.

3. Park YH, Min SK, Lee JN, et al. Comparison of survival probabilities for living-unrelated versus cadaveric renal transplant recipients. Transplant Proc 2004;36:2020-2. 